\title{
A Study on TQM Development, Performance and Sustenance in Service Industries through Effective Communication, Critical Success Factors and Market Orientation
}

\author{
Sendil Mourougan ${ }^{1}$,Dr. K. Sethuraman ${ }^{2}$ \\ ${ }^{\text {I}(B u s i n e s s ~ A d m i n i s t r a t i o n, ~ A n n a m a l a i ~ U n i v e r s i t y, ~ I n d i a) ~}$ \\ ${ }^{2}$ (Business Administration, Annamalai University, India)
}

\begin{abstract}
Total Quality Management (TQM) is a management philosophy which focuses on customer satisfaction by improving the organisation performance through co-ordination of various processes in all the business units. The purpose of TQM is to provide quality product or service to the customer which inturn provides increased productivity at low cost. TQM is applicable to all manufacturing service industries. It operates on the principle that cost of prevention is less than the cost of correction. This study focuses on TQM development, performance and sustenance in service industries through effective communication, critical success factors and market orientation. It examines the quality improvement through effective employee communication and the relationship between CSFs and company performance. The study suggests Deming's Plan-Do-Study-Act (PDSA) cycle based approach to develop and sustain TQM. It articulates the relationship between TQM and market orientation, in terms of both elements (practices) and performance. The study investigates the reasons for TQM failures and proposes guidelines for successful implementation of TQM.
\end{abstract}

Keywords: Critical Success Factors (CSFs), Effective Communication, Market Based Quality, PDSA, TQM Failures, and TQM Implementation

\section{Introduction}

TQM was introduced in mid 1980s by Edwards Deming, Joseph Juran and Kaoru Ishikawa. This approach aims at process improvement, waste reduction, business optimization and quality performance. Earlier empirical studies in TQM suggested that the successful implementation of TQM will result in improved employee involvement, improved communication, increased productivity, improved customer satisfaction, and improved competitive advantage. A strong competitive pressure has forced service industries to adopt QM tools and techniques to offer higher quality products and services as a way to delight and keep their customers intact. Many organizations have implemented TQM and identified CSFs for better business performance in order to improve their position in the global market which is now become an important research area in TQM.

\section{Total Quality Management}

TQM is characterized by its principles, practices, and strategies that emphasizes upon continuous improvement in quality, increased involvement of employees, commitment of top management, employee empowerment, teamwork, benchmarking, leadership, rewards and recognitions, feedback and relationship with suppliers. TQM models prescribe several important factors: starting with effective leadership that executes brilliant strategies, emphasizing best practices and quality improvements [1]. The factors fall into six factors: leadership, best practices, customer focus, employee focus, community focus and productivity focus.

There are several elements of TQM that must be adopted for TQM to work.

- There must be a common quality vision.

- There must be a commitment to organize for quality.

- There must be dedication to continuous improvement.

- Quality should be everyone's responsibility not just quality control and the CEO.

- People who work with the system know more about the system and they should be consulted when a process is being analyzed.

\subsection{TQM Practices}

TQM practices can be defined as "the critical areas which an organization must accomplish to achieve its mission by examination and categorization of their impacts". TQM practices as shown in Fig. 1 are the actions and processes that can be controlled by management to achieve the organizations goals and to attain its vision. The importance of defining the TQM practices for implementation is to increase the success rate, reduce delivery time, and prevent disillusioned state with continuous improvement programs. Better management of TQM practices will result in improved quality and increased financial performance for the organization. 


\begin{tabular}{|l|l|}
\hline \multicolumn{1}{|c|}{ TQM Practices } & Product Quality \\
\hline $\begin{array}{l}\text { - Leadership } \\
\text { - Strategic Planning } \\
\text { - Customer Focus } \\
\text { - Process Management } \\
\text { - Supplier Management } \\
\text { - Cross-Functional Training } \\
\text { - Cross-Functional Product Design } \\
\text { - Customer Involvement } \\
\text { - Employee Involvement } \\
\text { - Empowerment and Team work } \\
\text { - Continous Improvement }\end{array}$ \\
\hline
\end{tabular}

Figure 1. TQM Practices and its impact on organizational performance.

\subsection{Primary Elements Of TQM}

Total quality management can be summarized as a management system for a customer-focused organization that involves all employees in continual improvement. It uses strategy, data, and effective communications to integrate the quality discipline into the culture and activities of the organization. These elements as shown in Fig. 2 are considered so essential to TQM that many organizations define them, in some format, as a set of core values and principles on which the organization is to operate.

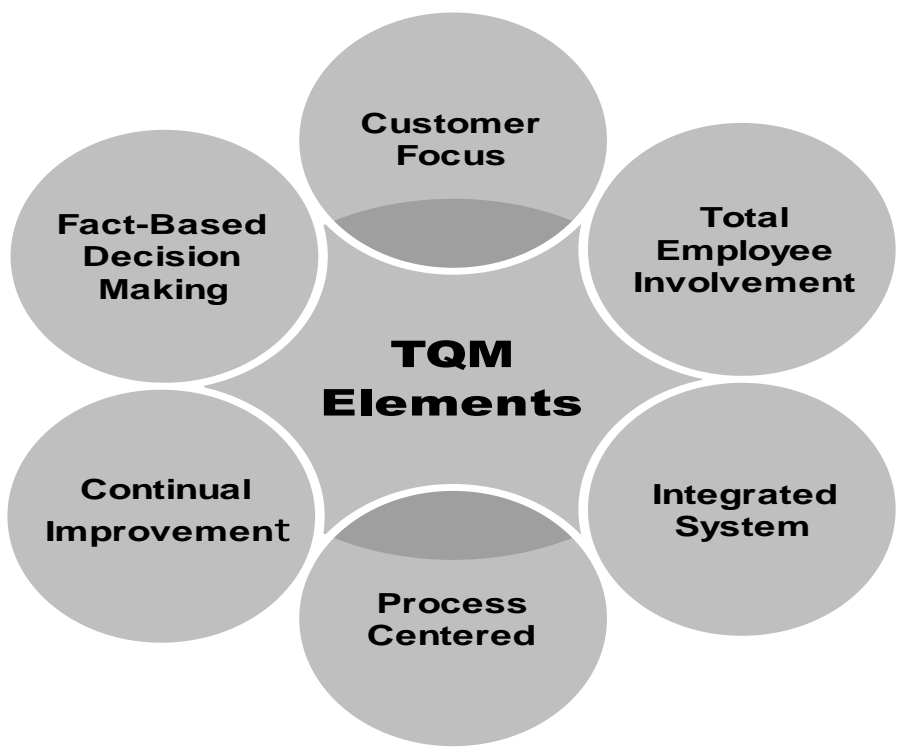

Figure 2. Primary Elements of TQM.

\section{TQM In Service Industries}

The growth of service industries has resulted in an increased focus on the implementation of TQM principles in service organizations and in delivering high-quality service to customers. The growth of service sector is due to the fact that service organizations cover a broad spectrum [2]. They interact directly with large number of customers. With the ever increasing competitive and tough market conditions, service organizations are concerned about their customer needs and requirements, and to satisfy them.

\subsection{Understanding The Service System}

Services industry can be defined as "An industry made up of companies that primarily earn revenue by providing intangible products and services." Service industries involve a large number of white-collar staff working with a purpose to satisfy the varying needs of customers. The service-producing sector includes the divisions of (1) transportation, communications, and utilities; (2) wholesale trade; (3) retail trade; (4) finance, insurance, and real estate; (5) public administration; and (6) services which includes etc., Other service industries includes personal services like dry cleaning, hair cutting, business services like business software developers, health care services, legal services, private education services, social services, mobile service providers, police and security system, internet service provider, real estate, retail services, non-financial services and many others where TQM concept can enrich the working style, service quality and performance [3]. 


\subsection{The Role of Top Management}

For TQM to be successful in an organization it must be actively supported by top management. If employees are confident that top management strongly supports TQM initiative, employees becomes involved in the TQM initiative. Successful employee empowerment and involvement are essential components of any TQM program. The reason for gaining the commitment of top management to implement the TQM programme is that management has the responsibility to help employees through all the different stages of TQM. Leadership is the heart and soul of change. Change will not occur without leadership.

Leaders must lead the pro-active change to TQM to overcome fear of change. Change to TQM demands stamina, a spirit of entrepreneurship, endless patience, continuous communication, encouragement and recognition of those who achieve successes along the line. It is a process that is exciting as well as dangerous. Cultural change should be planned and should occur in a consistent and incremental manner. To introduce TQM, an open cooperative culture has to be created by the management. Employees have to be made to feel that they are responsible for customer satisfaction. They are not going to feel this if they are excluded from the development of visions, strategies, and plans. It is important that they participate in these activities for complete success of TQM implementation. The success of an organization's quality efforts relies largely on focusing on the right objectives and its ability to communicate them to both its external and internal customers.

\section{Effective Communication}

Effective communication is important for any organization regardless of its size or nature. There is strong relationship between effective communication and successful quality implementation. TQM depends on communication that flows in all directions. For total quality to work, communication between all levels in the organization is vital. Thus it's important to note that without effective communication, TQM will not work in an organization [4]. Everyone must understand the vision, mission, and guiding principles as well as the quality policies, objectives, and critical processes of the organization. Business performance must be monitored and communicated continuously. The TQM approach integrates three basic fundamental aspects: commitment, culture and communication.

\subsection{Role of Effective Communication}

The message of quality improvement has to be communicated to three distinct audiences: employees, customers and stakeholders. Employees cannot be expected to be productive and effective if they do not receive accurate and relevant information. Effective communication increases employees' level of trust and improves problem solving. By allowing employees to give inputs with regard to their jobs, management recognizes that employees are an important source of knowledge and experience.

People's attitudes and behavior can be influenced by communication, and the essence of changing attitudes is to gain acceptance through excellent communication processes [5]. Positive reinforcement is an effective way to motivate people and generate their interest in transforming the organization. One of the most powerful ways to create interest in TQM is to communicate TQM success stories to employees. Success stories of organizations implementing TQM must also include financial information by teaching employees to understand and take TQM implementation forward.

The vehicles for communicating the total quality strategy to the organization's employee's are:

- Train and develop both managers and employees - Managers must understand the processes they manage as well as the basic concept of systems optimization.

- Employee training should focus on the integration and appropriate use of statistical tools and problem solving.

\subsection{Employee Communication}

The strategy and changes to be brought about through TQM should be clearly and directly communicated from top management to all employees. The first step is to issue a 'total quality message'. A signed TQM directive should follow this. People must know when and how they will be brought into the TQM process, what the process is, and the successes and benefits achieved. First-level supervision has an important role in communicating the key messages and overcoming resistance to change. The complexity and jargon in the language used between functional groups, needs to be reduced. Simplify and shorten are the guiding principles. Open' methods of communication and participation should be used at all levels. Barriers may need to be broken down by concentrating on processes rather than 'departmental' issues. · Top management must ensure that each group sees TQM as being beneficial, through communication. 


\subsubsection{Communicating The TQM Message}

A business can flourish when all objectives of the organization are achieved effectively. For efficiency in an organization, all the people of the organization must be able to convey their message properly. Quality must be carefully defined and metrics should be agreed upon. Communication should be up \& down. Employees should be assigned measurable goals.

Employees in most organizations fall into one of four groups, namely Senior Mangers, Middle Managers, Supervisors (first line or junior managers) and Operators. Senior management needs to ensure that each group sees TQM as being beneficial to them. Total quality training material and support (whether internal from a quality director and team or from external consultants) will be of real value only if the employees are motivated to respond positively to them. The key medium for motivating the employees and gaining their commitment to quality is face-to-face communication and visible management commitment.

\subsubsection{Communicating the Quality Strategy}

The essence of changing attitudes is to gain acceptance for the need to change, and for this to happen it is essential to provide relevant information, convey good practices, and generate interest, ideas and awareness through excellent communication processes. This change will require direct and clear communication from the top management to all staff and employees, to explain the need to focus on processes.

Everyone will need to know their roles in understanding processes and improving their performance. An excellent way to accomplish this first step is to issue a total quality message that clearly states top management's commitment to quality and outlines the role everyone must play. This can be in the form of a quality policy or a specific statement about the organization's intention to integrate quality into the business operations.

Sample-1: We can become a total quality organization only with your commitment and dedication to improving the processes in which you work. We will help you by putting in place a program of education, training, and teamwork development, based on business and process improvement, to ensure that we move forward together to achieve our business goals.

Sample-2: We wish to convey to everyone our enthusiasm and personal commitment to the total quality approach, and how much we need your support in our mission of business improvement. We hope that you will become as convinced as we are that business and process improvement is critical for our survival and continued success. The quality director or TQM coordinator should then assist the senior management team to prepare a directive. This must be signed by all business unit, division, or process leaders, and distributed to everyone in the organization.

\section{The directive should include the following:}

- Concept for total quality.

- Importance of understanding business processes.

- TQM approach and Individual and process group roles and responsibilities.

- Principles of process measurement.

\subsubsection{Communication To Ensure Service Quality}

Communication to the customer should clearly reflect what customers will actually receive during service rendering and must help customers to understand their role in the service rendering process. Just like leadership, communication plays a primary role in an organization's service rendering to improve service quality. The service quality of an organization can improve by means of accurate and applicable communication with the customer. Inadequate horizontal communication and an inclination to make promises that are not kept, is the biggest cause of gaps between customers and organizations. This problem can be solved and lessened by ensuring that communication with the customer does not create unnecessary expectations that cannot be met. Internal communication between sections at the organization must be improved and communication with the customer should focus on the quality dimensions and characteristics that are the most important to the customer.

\subsection{Supportive Dimensions For Effective Communication \\ 4.3.1 Clear Communication}

The first supportive dimension that influences the success of a TQM effort is communication. By virtue of the supportive dimensions, communication plays a key role in the TQM effort. In order to successfully implement TQM activities in an organization, executives must have to communicate effectively. 


\subsubsection{Training}

The second supportive dimension that influences the success of a TQM effort is training. To successfully implement TQM activities at an organization, executives must be trained effectively to implement TQM. Experience has shown that a successful TQM training strategy should have the following objectives

- All members of the organization should be trained.

- Training should be based on the work actually performed by the employees involved and follow the format: (1) concepts, (2) case studies and (3) application to own job.

- Managers should lead the training of their work groups and be responsible for their effectiveness.

- Training should be cascaded down from the top of the organization, thus enabling senior managers to provide role model leadership.

Training in technical, administrative, problem solving, quality management, productivity improvement and interpersonal skills is necessary to varying degrees across teams and organizational levels. Awareness training should cover topics such as: (1) the organization's mission statement, (2) structure and functions of teams, (3) the relationships between teams and ongoing quality and productivity programmes, (4) reasons for the shift to teams, (5) the transition to teams, (6) new roles and responsibilities, (7) team member selection, (8) pilot projects, (9) compensation and reward structures, (10) team scope, and (11) job security.

Consultants should be contracted to provide a substantial portion of the training. While lacking in organisation-specific experience, they bring a wealth of information and experience from their work in other organisations. Further, they are often more believable and competent teachers than insiders.

\subsubsection{Culture forming}

The third supportive dimension that influences the success of a TQM effort is culture forming. Every organization has a unique work culture, and it is virtually impossible to achieve excellence in its products and services unless a good quality culture has been fostered. Thus, an integrated system connects business improvement elements in an attempt to continually improve and exceed the expectations of customers, employees, and other stakeholders. Culture forming is a critical success factor to implement TQM. It is essential that a thorough study be made to determine whether the organization is ready for the implementation of TQM as it can have a major impact on the culture of an organization. The beliefs, behaviors, norms, dominant values, rules and climate in the organization form the culture of the organization. Any organization needs a vision framework, comprising its guiding philosophy, core values and beliefs, purpose and mission.

If the culture is positive, it enables the implementation of new management strategies or philosophies as well as the smooth functioning of the organization. The absence of culture in an organization is one of the main reasons why transformation to TQM fails. An organization's culture is based on the organization's mission, vision, values and its requirements for success, namely high quality, reliability, customer service, innovation, hard work and loyalty. Changing people's beliefs and attitudes is mainly obtained by means of experience, observation, interaction, participation and persuasive communication.

Before embarking on a quality revolution, an organization must determine whether its culture offers an environment that is conducive to total quality. If not, the culture must be changed. Changing the culture within an organization is one of the dimensions required to move an organization from a hierarchical, traditional organization to an empowered organization. All existing and newly appointed employees should be made aware of behaviour that is regarded as the best way of action. Every employee who adopted the new organizational culture of TQM must assume ownership of their processes and the quality of their deliverables. To really understand what is meant by the culture of an organization, it is important to clearly define the concept. The culture in each organisation tends to have distinctive properties that make it different from other organisations such as (1) top-down leadership, (2) vision, (3) customer focus, (4) employee well-being, (5) performance management system, (6) reward system, (7) communication system, (8) roles and relationships, (9) structure and (10) teamwork.

Certain conditions are essential for a successful change in culture, namely:

- Top management's commitment to the TQM programme, as well as their visible involvement, is important.

- Leaders must exhibit the new desired behaviour and their general behaviour should be in accordance with slogans based on their vision, mission and values.

- Clear objectives should be formulated - these should include objectives with regard to performance, programming and cultural expectations.

- Change should be regarded as a process to build skills, of which training forms an important component. The change process should take place simultaneously in all subsystems in the organization.

- A compensation or recognition system should be linked to the desired behaviour or actions.

- Sufficient time should be allocated to ensure the success of the project.

- The programme should be result-orientated. 


\section{Critical Success Factors}

Many organizations have implemented TQM and identified TQM practices/CSFs for better business performance in order to improve their position in the global market. TQM aims to continuously improve the performance of products, processes, and services to achieve and surpass customer's expectations. To achieve this, key factors termed as "Critical Success Factors (CSFs)" has to be identified. CSFs can be defined as "the critical areas which organization must accomplish to achieve its mission by examination and categorization of their impacts". Table 1 shows the CSFs introduced by various authors and commonly deployed.

Table 1 TQM Critical Success Factors

\begin{tabular}{|c|c|}
\hline TQM CSFs introduced by various authors & $\begin{array}{c}\text { Commonly employed critical success factors across } \\
\text { organisations }\end{array}$ \\
\hline $\begin{array}{ll}\text { - } & \text { Employer relation/empowerment } \\
\text { - } & \text { Top management/ leadership } \\
\text { - } & \text { Quality polices,/process management } \\
\text { - } & \text { Training } \\
\text { - } & \text { Quality technology / process design (SQC) } \\
\text { - } & \text { Supplier quality management } \\
\text { - } & \text { Quality planning/ product design (service) } \\
\text { - } & \text { Role of quality department } \\
\text { - } & \text { Team work structures } \\
\text { - } & \text { Customer satisfaction orientation } \\
\text { - } & \text { Strategic quality management } \\
\text { - } & \text { Communication of information } \\
\text { - } & \text { Benchmarking } \\
\text { - } & \text { Zero defect }\end{array}$ & $\begin{array}{ll}\text { - } & \text { Top management commitment and leadership } \\
\text { - } & \text { Customer focus } \\
\text { - } & \text { Information and analysis } \\
\text { - } & \text { Training } \\
\text { - } & \text { Supplier management } \\
\text { - } & \text { Strategic planning } \\
\text { - } & \text { Employee involvement } \\
\text { - } & \text { Human resource management } \\
\text { - } & \text { Process management } \\
\text { - } & \text { Teamwork } \\
\text { - } & \text { Product and service design } \\
\text { - } & \text { Process control } \\
\text { - } & \text { Benchmarking } \\
\text { - } & \text { Continuous improvement } \\
\text { - } & \text { Employee empowerment } \\
\text { - } & \text { Quality assurance } \\
\text { - } & \text { Social responsibility } \\
\text { - } & \text { Employee satisfaction }\end{array}$ \\
\hline
\end{tabular}

CSFs are those vital construct that must go well to ensure success for a manager or an organization, and therefore, they represent those managerial or organizational areas that must be given special and continual attention to bring about increased performance [6]. CSFs are not objectives, but are the actions and processes that can be controlled by management to achieve the organizations goals. The importance of defining the CSFs of TQM for implementation is to increase the success rate, reduce costs, and prevent disillusionment with continuous improvement programs. Hence, better management of such CSFs will result in improved quality and increased financial performance for the organization.

Implementing TQM involves defining and deploying several key elements or factors. One of the problems of critical factors of TQM is how to define them and what should be the measure of their impact before they become critical. CSFs of TQM are latent variables, which mean they cannot be measured directly. Past evidences have shown that TQM programs have failed because the success factors were not in place.

\section{Market Orientation}

TQM and Market orientation as strategic initiatives have been associated to improve organizational effectiveness and financial performance.

\subsection{Effects of TQM practices on market orientation}

Gaining market advantage is the objective of market orientation that is the result of responding to changing customer needs earlier or better than competitors. A market advantage means a firm is generating supernormal profits by getting more customers, keeping them longer, or charging higher price for the products that are valued by the customers. Other than differentiation (pricing) and customer relationships, market advantage can be exploited through intangible strategic assets like reputation, patents, trademarks, brand equity, knowledge and learning orientation. Achieving market advantage is also possible by leveraging technological innovation, mass customization, globalization, and competitive orientation strategies such as benchmarking, positioning and competitive objective setting. Branding, for example, is a most powerful form of differentiation that can create lasting market advantage because of its not imitable characteristic. Brand equity, the newer concept than brand image and brand loyalty, is putting value to the brand and nurturing this value through investment in advertising and communication. Brand equity is therefore a measure of market advantage created by the brand [7]. Customer patronage of a brand however, is sustainable only when operation performance and product reliability eventually meet the expectation of the brand. Similarly, patents, trademarks, reputation all are dependent on the effectiveness of operational excellence to produce consistency of quality performance in the marketplace. 
Quality performance under TQM perspective directly affects customer perceived quality outcome. For example, product features, reliability, operations flexibility, singly and in combination enable strategies of product variety, reputation, and customization. Additionally, these factors form the basis for product differentiation; offering product with distinctive features by design, engineering variables or communication variables. Product differentiation in combination with market knowledge, in turn made possible the varietybased positioning, need-based positioning, and access based positioning, which constitute three sources of strategic positioning. In conclusion, quality performance will enable firms to exploit advantageously market opportunities.

\subsubsection{Market Advantage}

Customer-oriented firms should convert customer satisfaction to customer retention and loyalty and creating customer partnership realizing that all those are important drivers to profitability. It can be postulated that TQM companies that establish customer relationships are likely to retain customers and achieve higher profitability. Long-term customer relationships would likely easier to create structural bonding such as joint investment in value delivery system which create difficult-to-imitate competitive advantage hence are likely sustainable. Market advantage in terms of customer oriented strategies mean that firms can improve customer retention rate thus lead to substantial improvement in profits.

\subsubsection{Positional Advantage}

Positional advantage is created in the market place when firm perform the value delivery activities differently from competitors, or perform different activities from competitors. This is the meaning of strategy. In either case, it is also means strategic positioning or differentiation strategy-deliberately choosing a different set of activities to deliver a unique mix of value. Firms pursuing cost leadership strategy could accept cheaper components; use standardized processes, and advancing market share in order to reduce unit costs. Some TQM practices such as process improvement, changeover flexibility, variety flexibility and efficient design, zero defect and the like, allow some cost containment be achieved. Simply stated, TQM efforts help to make cost leadership strategy possible. At the same time TQM efforts also help firms to support market advantage created by their marketing activities.

\subsection{Integrating TQM And Market Based Quality (MBQ) Elements}

When discussing TQM and market orientation relationships it is important to differentiate between practices (elements) and performance. Practices, being inputs to achieve performance outcome influence the latter directly and singly or through interaction with other input variables. Those conceptually different and similar elements are shown in Table 2. These elements are assembled as Market-Based Quality (MBQ) elements.

Table 2. Unique and common elements of MBQ orientation

\begin{tabular}{|c|c|c|}
\hline M Ele & on Elements & Unique Market Or \\
\hline $\begin{array}{ll}\text { - } & \text { Supplier Management } \\
\text { - } & \text { Usage of Quality/SPC } \\
& \text { tools } \\
\text { - } & \text { Operational Optimization } \\
\text { - } & \text { Employee Involvement } \\
\text { - } & \text { Product / Service } \\
& \text { Reliability } \\
\text { - } & \text { Continuous Improvement } \\
\text { - } & \text { Quality Training } \\
\text { - } & \text { Empowerment } \\
\text { - } & \text { Team work } \\
\text { Bench marking }\end{array}$ & $\begin{array}{ll} & \text { Customer Orientation } \\
\text { - } & \text { Management Commitment } \\
\text { - } & \text { Interfunctional } \\
& \text { coordination } \\
\text { - } & \text { Knowledge and Learning } \\
\text { - } & \text { Design Optimization } \\
\text { - } & \text { Market Advantage } \\
\text { - } & \text { Measurement } \\
\text { Customer Satisfaction }\end{array}$ & $\begin{array}{ll}\text { - } & \text { Design Optimization } \\
\text { - } & \text { Process Optimization } \\
\text { - } & \text { Product, Service Reliability } \\
\text { - } & \text { Technological Orientation } \\
\text { - } & \text { Competing-Mix modification } \\
\text { - } & \text { Customer Relationshion } \\
\text { - } & \text { Innovation Orientation } \\
\text { - } & \text { Strategic Positioning } \\
\text { - } & \text { Branding } \\
\text { - } & \text { International Marketing } \\
\end{array}$ \\
\hline
\end{tabular}

\section{Sustaining TQM}

Sustainability is defined as 'the ability of an organization to adapt to change in the business environment to capture contemporary best practice methods and to achieve and maintain superior competitive performance'. Sustainability is described as the development that meets present needs without compromising the ability of future generations to meet their own needs. Without sustainability, there is little benefit to be gained from TQM.

\subsection{PDSA Cycle For Sustainable Development Of TQM}

This paper suggests Deming's Plan-Do-Study-Act (PDSA) cycle based approach to develop and sustain TQM. This approach is unique and can be customized to suit the organisation requirements [8]. The results will help 
the top management in setting out priorities to achieve sustained growth of TQM process. The PDSA cycle suggested for TQM sustainability consists of four steps:

- Step-1: Plan for TQM - The adoption of TQM in an organization has to start from a strategy for implementation involving the planning and preparation of document detailing the way forward. The preparation of such a document may constitute: (1) Creation of a TQM co-ordination body; (2) Development of a vision, mission and policy statements; (3) Education for the top management and coordinating body members on total quality principles and philosophy; (4) Selection and trial run of the first improvement project; and (5) Appraising the company's current level of quality management implementation.

- Step-2: Implement TQM.

- Step-3: Study and measure the level of implementation of TQM.

- Step-4: Take necessary actions to improve the less developed programs of TQM.

\subsection{MBQ Elements And Sustainable Performance}

Firm that implement TQM can derive competitive advantage in the market place as well as from the operational processes. In the market place, created positional advantage can produce increased market share and increase revenue. Internally, improved design can lead directly to efficient process, which can reduce defective production. Effective and efficient design would yield directly both improved product reliability and market reputation Improved reliability is a resulted after the customers use the product or experience the service, hence has its time lapse before its effect can be recognized. However, once reputation on reliability has been built, repeat purchase is more likely. Reputation, rooted in product reliability is therefore a source of competitive advantage, which is more sustainable because it is harder for competitor to imitate. Design optimization, process optimization and product or service reliability by themselves are sources of quality advantage. In essence, design optimization, process optimization and product reliability are prerequisites to lowering product costs and achieving operational excellence.

\subsubsection{Design optimization and sustainable performance}

Design optimization includes activities that allow firms to use cost-effective input in product design and develop better product faster than competitors thus reduce new product cycle time to meet time-based competition. Optimization in design would improve defect in production through design for Producibility and by using fewer components. It would also enable firms to increase process optimization through efforts such as plant modernization, facilities expansion, and re-layout, redesign and reengineering. Design optimization also enables firms to combine and utilize existing standardized components to create new models or services more effectively and drastically reduce product development costs. Thus Design optimization helps the firm to sustain in the market by providing better quality product or service.

\subsubsection{Process optimization and sustainable performance}

Process optimization refers to various organizational capabilities and practices to control and achieve efficient operations in the value delivery processes. It aims to lower product costs while ensure quality of conformance to design. Constant improvement in process may lead to best practices, which can be reflected through high plants and facilities utilization; labour efficiency; reduced scrap, waste and rework; increased product and service reliability; and reduced relative operating costs. Through TQM efforts productivity is achieved without specifically resulting in reduced headcount, unlike downsizing, rightsizing, delayering, or reengineering, which almost always do. Effective process management improves quality performance through reduction of process variance and defective production. Process flow management practices include reliance on preventive maintenance, fool proofing or poka-yoki, flexible and effective scheduling, and teamwork between managers and operatives in quickly solving operations problems. Therefore, TQM companies that improve process optimization will be able to control operational costs and achieve sustainable performance.

\subsubsection{Product, Service reliability and sustainable performance}

Quality leadership is based on thrust to become a leader in industry through achieving high standards in the product performance, reliability and features, at competitive cost. High reliability creates product or service reputation, which is also a component of company reputation and source of market advantage. By leveraging this reputation as strategic asset firm can charge premium price in the market. High product and service reliability has been shown to be associated with fewer complaints, lower warranty costs, reduced service costs after sale, higher customer satisfaction and perceived market quality. Perceived product performance relative to competitor's products can create differential advantage and reputation, which is likely to sustain firm's performance. 


\section{Guidelines To Effective TQM Implementation}

Successful implementation of TQM program in service organization can be achieved by adopting a set of TQM practices and developing a model or framework based on these practices to get maximum benefits and desired outcome. The set of practices chosen depends upon the nature and characteristics of the service organization which is responsible for successful implementation of TQM program. For effective implementation of TQM and better results, following ten basic steps are identified.

- Adoption of state-of-art and advanced technologies instead of following traditional culture by the topmanagement in the organization. Thus, top-management commitment is crucial to success.

- Set the objectives or goals by involving employees at all levels and define them. This will act as the indicators of success in terms of mission.

- Developing quality awareness, imparting training and education on the principles and core concept of TQM to the employees, changing their attitudes and mind set towards quality culture, and commitment of never ending the continuous improvement and innovation in the organization.

- Develop and document the approach to TQM and make sure that it is being practiced in the organizations and should not remain on papers only.

- Identify the key TQM practices for the organization and create an environment to implement and restrain them by force.

- Prioritize the key TQM practices into different categories and focus on most important practices/categories responsible for improving the organization performance.

- Further, breakdown the key TQM practices into sub-categories, activities, or tasks and form improvement teams.

- Continuously monitor and control the process in response to the difficulties observed from feedback mechanism in the changed process.

- Develop quality improvement teams to solve the quality related issues in quick time without delays. Communicate all the relevant activities, progress and result to the team members and management.

- Frequently review and improve the quality plans and measure performance.

Without a strategy to implement TQM the effort will lead to frustration of employee and thus, leads to the total failure of the TQM implementation [9]. Therefore, all the employees should have prior knowledge of TQM and must be educated and trained before TQM is initiated for implementation. Implementation of TQM takes time as well as effort, and organizations must not regard TQM approaches as quick-fixes.

\subsection{Organisation Support}

Studies seem to indicate that TQM-adopting firms obtain a competitive advantage over firms that do not adopt TQM. Firms that focus on continuous improvement, involve and motivate employees to achieve quality output and focus on satisfying customers' needs are more likely to outperform firms that do not have this focus. Thus, we can expect that to the extent an organization implements TQM practices, performance should be enhanced. Fig. 4 shows the effect of organisation support on TQM implementation.

\subsection{Co-Worker Support}

For firms implementing TQM practices, higher co-worker support is likely to be associated with enhanced organizational performance as shown in Fig. 3.

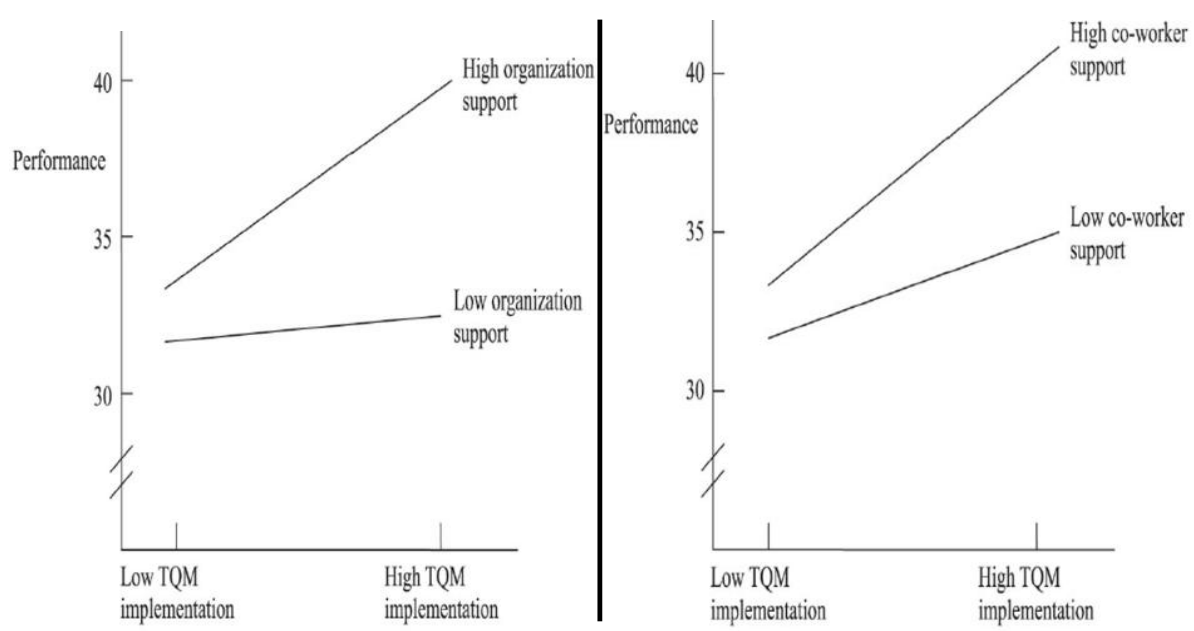

Figure 3. Effect of Organization support and Co-worker support on TQM implementation 
Co-worker support refers to co-workers assisting one another in their tasks when needed by sharing knowledge and expertise as well as providing encouragement and support. For example, colleagues may share their knowledge and expertise when an employee is faced with a difficult and novel task for which a solution is not readily available. Employees may also acquire task-relevant knowledge and expertise from supportive coworkers, which may make new ways of doing things possible.

In this context, working with helpful, supportive colleagues promotes an environment where new ideas can be discussed more openly and freely. It appears evident that working with supportive co-workers who readily share task-relevant information and expertise is more likely to be associated with successful TQM implementation.

\section{TQM Failures And Symptoms}

Many organizations have been using TQM to improve performance and they are quite successful in implementing it, there are also some cases where organizations have failed to reap the benefits of TQM due to their different focus in its implementation. Results do not always come quickly. It is generally acknowledge that the longer organizations work at TQM, the more successful they will be. Two to three years into implementation have been quoted in the literature as the period after which some tangible benefits of TQM are more likely to be evident [10]. The success of implementing TQM in an organization is ultimately judged by its customers.

\subsection{TQM Failures}

A TQM initiatives is therefore, considered a failure if it fails to delight customer and add value for customer satisfaction. It is not surprising to note that these are as many TQM failures as there are success stories. Some of the common reasons for TQM setbacks and failures are:

- inadequate attention to different CSFs/QM practices during TQM implementation in the service organizations;

- failure to develop an implementation framework that fits to a specific service organization, instead a more generic model or a copy of a system that was successful for another organization was used;

- lack of top and middle management commitment, unrealistic expectations and time-frame, and cost of TQM implementation, under-reliance on statistical methods, and failure to develop and sustain a quality-oriented culture;

- $\quad$ high expectations of quick results from TQM initiatives;

- management reluctance in imparting training and education programs to employees for better understanding of TQM philosophy and use;

- lack of consensus, lack of employee empowerment, poor planning, lack of communication, management causing confusion, cross functional teams are not employed, and lack of direction and purpose;

- no targets, no attitude to attain higher productivity, lack of continuous improvement culture, lack of coordination between department, employee's resistance to change, and best practices of other companies are not benchmarked may be some of the other major reasons that causes the failure of TQM efforts.

Many organizations jumped on the TQM bandwagon thinking that if they copy the tools and techniques, they will reap the benefits of TQM. It looks at quality as a long-term business strategy, which strives to provide products and/or services to satisfy fully both internal and external customers by meeting their explicit and implicit expectations.

\subsection{TQM failure symptoms}

The following are some of the symptoms for TQM process not working.

- The results are not visible;

- Top management commitment is not seen and is not felt;

- Middle management does not know precisely what is expected of them in relation to the TQM process;

- Low degree of employee involvement; and

- The organization changes priorities often and as a result quality decreases.

\subsection{Theoretical Implications}

\section{Discussion}

This study examined the TQM development, performance and sustenance in service industries through effective communication, critical success factors and market orientation. This study also found that an environment of support within the organization enhances the effectiveness of TQM implementation [11]. More specifically, organization support that encourages a positive reciprocal relationship between employees and their organizations, and strong collegial support that promotes sharing knowledge in an encouraging, supportive manner produce a synergistic effect on the TQM/performance relationship.

DOI: $10.9790 / 487 X-1905030112 \quad$ www.iosrjournals.org $\quad 10 \mid$ Page




\subsection{Managerial Implications}

This study has important implications for managers. First, it motivates managers (and provides a justification) to invest in the time and resources to implement TQM programs. Based on the results of this study, the implementation of TQM practices is associated with enhanced organization performance.

Second, this study signals the importance of ensuring a supportive organizational environment for the effective implementation of TQM. The study suggests that organizations should develop an environment or "culture" of support, which includes fostering support among co-workers, for the effective implementation of TQM. If employees do not feel there is sufficient acknowledgement and support from the organization and from colleagues with whom they work, then firms may not reap the benefits of TQM programs.

Some of the managerial implications of the present study are:

- The results of the present study will help managers and practitioners in smoother implementation of TQM program in service industries.

- Managers can use a set of "vital few" CSFs in their organization and link them with both operational and organizational performance.

- Managers can benchmark their organizations with "vital few" CSFs and can identify gaps.

- Managers can get the full benefits of TQM by training all employees at all levels in order to develop awareness, interest, and action towards TQM program. Thus, role of top-management commitment and leadership might be fruitful in the development and successful implementation of appropriate training program on TQM.

Managers and practitioners of service industries should also consider suppliers as important business partners. They have to be involved in development of improved products and services, improved process, quality information and data management, and initiating the quality policy. This may result to better quality and hence, increased customer satisfaction.

\section{Recommendation}

It is recommended that total quality management approach is a major discovery in the history of business and management. It is a reliable tool in the hands of organization management to practice and enjoy the taste of success with the dedicated and trained work force. The companies who are not focusing on delivering quality would suffer and can become bankrupt. So total quality management be adopted and quality should be observed in day to day matters for optimization.

Although this study successfully achieves the set objectives, there are opportunities for further research. Further in-depth investigation needs to explore other critical issues of TQM implementation like performance measurement, total environmental quality management (TEQM) etc., for better understanding of tools and techniques of TQM to measure the efficiency and effectiveness of service organizations [12].

\section{Further, it is recommended that:}

- Top-management of service industries needs to understand the importance of quality culture as a strategic weapon.

- Top-management of service industries needs to communicate and describe quality goals and policies to internal employees.

- Regular participation of top-management team in the process will motivate employees to take active part in quality activities.

- Service industries needs to train and educate their employees regularly on industries operations and statistical skills.

- Service industries needs to ensure that they should maintain and think about continuous improvement and innovation. This is never ending task. They should adopt new strategies to improve company responsiveness to customer's complaints.

\section{Conclusion}

The study emphasizes the importance of implementing a comprehensive TQM program. It is more systematic in explaining the fundamentals and components of TQM. The study covered theory, concepts of $\mathrm{TQM}$, its practices, service system together with the reasons of TQM failures, and approach to TQM implementation.

\section{This Study Makes A Real Contribution In:}

- understanding the service system and the reasons for its growth;

- understanding TQM in service organization and its impact;

- understanding the role of TQM practices in service organizations;

- Knowing what causes 'TQM failure'?

- Understanding how TQM can effectively be implemented for better result?

DOI: $10.9790 / 487 X-1905030112 \quad$ www.iosrjournals.org $\quad 11 \mid$ Page


From the study, it is also concluded that organizations that want to implement TQM effectively must have patience because TQM takes a long time to get implemented and to have fruitful results. It requires major changes in cultural aspects as well as employee mindset in an organization. This study will help service managers in better understanding of TQM and service quality concept, and their implementation in their organizations by considering the top-management commitment and customer focus as most important principles for service organizations. It will also help them to motivate and create a vision for the change.

\section{References}

[1]. E. Allen and R. Brady, "Total quality management, organisational commitment, perceived organisational support and intraorganisational communication”, Management Communication Quarterly, 10(3), 1997, 316-41.

[2]. S. A. Brah, J. L. Wong and B. M. Rao, TQM and business performance in the service sector, International Journal of Operations and Production Management, 20(11), 2000, 1293-1312.

[3]. F. Talib. et al., Total Quality Management in Service Sector: A Literature Review, International Journal of Business Innovation and Research, 6(3), 2012, 259-301.

[4]. D.C. Barnlund, A transactional model of communication (Boston, MA: Pearson Education, Inc., 2008)

[5]. Roy M. Berko, et al., Communicating (Boston, MA: Pearson Education, Inc., 2010)

[6]. A. Seetharaman, et al., Critical Success Factors of Total Quality Management (Boston, MA: Pearson Education, Inc., 2006)

[7]. C. Narver John and F. Slater, "The Effect of a Market Orientation on Business Profitability," Journal of Marketing, 54 (10), 1990, 20-35.

[8]. M. A. Idris and M. Zairi, Sustaining TQM: A Synthesis of Literature and Proposed Research Framework, Total Quality Management \& Business Excellence, 17(9), 2006, 1245-1260.

[9]. R.P. Mohanty and R.P. Lakme, Factors affecting TQM implementation: An empirical study in Indian Industry, Production planning \& control, 9(5), 1998, 511- 520.

[10]. O. Harari, Ten reasons why TQM doesn't work, Management review, 82(1), 1993, 33-38.

[11]. F. Talib. et al., An Empirical Investigation of Relationship between Total Quality Management Practices and Quality Performance in Indian Service Companies, International Journal of Quality and Reliability Management, 30 (3), 2013a, 280-318.

[12]. S.L. Ahire, R. Landeros and D.Y. Golhar, "Total quality management: a literature review and an agenda for future research", Production and Operations Management, 4(3), 1995, 277-30. 